\title{
FENOLOGIA E PRODUÇÃO DA AMOREIRA-PRETA SEM ESPINHOS CV. XAVANTE NA REGIÃO DE GUARAPUAVA-PR
}

\section{PHENOLOGY AND YIELD OF THORNLESS BLACKBEERY CV. XAVANTE IN THE REGION OF GUARAPUAVA-PR}

\author{
Renato Vasconcelos BOTELHO ${ }^{1}$ \\ Alexandre Pozzobom PAVANELLO ${ }^{2}$ \\ Doglas BROETTO ${ }^{3}$ \\ Scheila de Fátima SCISLOSKI ${ }^{2}$ \\ Tiago Celso BALDISSERA ${ }^{2}$
}

\begin{abstract}
RESUMO
Este trabalho teve como objetivo avaliar o comportamento da amoreira-preta sem espinhos cv. Xavante em Guarapuava (PR) entre os anos de 2005, 2006 e 2007. Foram avaliadas semanalmente vinte plantas para as variáveis porcentagem de brotação e porcentagem de florescimento. Os frutos de amora-preta foram colhidas duas a três vezes por semana e nos dois primeiros ciclos os frutos foram avaliados para massa média e teor de sólidos solúveis totais. A cv. Xavante apresentou boa adaptabilidade para a região de Guarapuava com brotação regular entre a segunda quinzena de agosto e final de setembro, floração entre início de outubro e meados de novembro e colheita de final de novembro a final de janeiro. A produtividade situou-se entre $2.790,5$ e $5.952,9 \mathrm{~kg} \mathrm{ha}^{-1}$, a massa média entre 4,3 e $5,1 \mathrm{~g}$ e o teor de sólidos solúveis entre 8,3 e $10,1 \%$.

Palavras-chave: Rubus spp.; Rosaceae; pequenos frutos; amora-preta; fruteiras de clima temperado.
\end{abstract}

\section{ABSTRACT}

This work aimed to evaluate the behavior of thornless blackberry plants cv. Xavante in Guarapuava (PR), Brazil in 2005, 2006 and 2007. Twenty plants were weekly evaluated for sprouting percentage, and anthesis percentage. The blackberries were harvest twice or three times per week and in the first two seasons the fruits were evaluated for fruit weight and soluble solids content. The blackberry plants cv Xavante showed good adaptability in Guarapuava-PR, with regular sprouting between second-half of August and end of September, anthesis from beginning of October and middle of November and harvest between end of November and end of January. The estimated yield was between 2,790.5 and 5,952.9 $\mathrm{kg} \mathrm{ha}^{-1}$, the fruit mean weight was 4,3 and $5,1 \mathrm{~g}$ and the soluble solids content was 8,3 and $10,1 \%$.

Key-words: Rubus spp.; Rosaceae; small fruits; blackberry; temperate fruit zones.

\footnotetext{
${ }^{1}$ Eng. Agr. Dr. Prof. Adjunto. Departamento de Agronomia, Universidade Estadual do Centro-Oeste (UNICENTRO). R. Simeão Varella de Sá, 03, CEP 85040-080. Guarapuava, PR - Brasil. E-mail: rbotelho@unicentro.br. Bolsista CNPq PQ-2

2 Acadêmicos do curso de Agronomia, Universidade Estadual do Centro-Oeste, Guarapuava, PR - Brasil. E-mail: alexandrepavanello@hotmail.com, tiago_baldissera@hotmail.com, sheila_agronomia@hotmail.com.

${ }^{3}$ Bolsista PIBIC Júnior/CNPq/Fundação Araucária, Guarapuava, PR - Brasil. E-mail: doglasbroetto@hotmail.com.
} 


\section{INTRODUÇÃO}

Situada no terceiro planalto paranaense, o município de Guarapuava (PR) é Pólo Regional da região denominada Centro-Oeste que abrange 24 municípios e uma população de aproximadamente meio milhão de habitantes. Esta região apresenta um dos mais baixos Índices de Desenvolvimento Humano do Estado do Paraná (IDH $=0,773$ ) (PNUD-BRASIL, 2008) e reúne as condições sócioeconômicas e edafo-climáticas adequadas para o desenvolvimento da fruticultura de clima temperado, podendo ser uma atividade promissora, principalmente para as inúmeras propriedades familiares da região (Fávaro et al., 2004).

Dentre as várias opções de espécies frutíferas com boas perspectivas de comercialização, encontra-se a amoreira-preta (Rubus spp.), como uma das mais promissoras (Antunes \& Raseira, 2004). No Brasil, estima-se que existam apenas 300 ha plantados desta rosácea no sul de Minas, região de Jundiaí, Curitiba e Palmas no Paraná, com cultivos em Santa Catarina e Rio Grande do Sul. Estes cultivos, em sua maioria, são em pequenas propriedades. A fruta fresca tem grande mercado. Em algumas regiões, como as de Pelotas, Antônio Prado e Vacaria, pequenas cooperativas já transformam a produção em geléias e sucos (Antunes, 2005).

Devido ao baixo custo de implantação, manutenção do pomar e, principalmente, reduzida utilização de agrotóxicos a cultura se apresenta como boa opção dentro da agricultura familiar. Cultura de retorno rápido, pois no segundo ano entra em produção, dá ao pequeno produtor opções de renda, destinando seu produto ao mercado in natura, indústria de produtos lácteos e congelados, e fabrica de geléias caseiras (Antunes, 2002).

Sendo planta exigente em frio, os aspectos fenológicos da amoreira-preta podem variar de ano para ano em função desta exigência em frio ter sido ou não satisfeita. Além de aspectos climáticos, fatores inerentes à espécie e/ou variedade podem afetar o comportamento da planta (Antunes et al., 2000).

A cultivar Xavante, lançamento conjunto da Embrapa Clima Temperado e da Universidade de Arkansas é resultante de sementes coletadas em Clarksville, AR, EUA, de uma população resultante de cruzamento entre as seleções A-1620 e A-1507, sendo, portanto, a segunda geração deste cruzamento. As suas hastes são vigorosas, eretas e sem espinhos. É uma cultivar de baixa necessidade em frio e boa produção. Para as condições do sul do Brasil, a floração se inicia em setembro e estende-se até outubro. A maturação é precoce e a colheita inicia em meados de novembro. As frutas têm forma alongada, firmeza média, sabor doceácido, predominando a acidez, com teor de sólidos solúveis em torno de $8^{\circ}$ Brix. O tamanho das frutas é bom, com massa média próxima a $6 \mathrm{~g}$ (Antunes \& Raseira, 2004).

Este trabalho tem como objetivo avaliar a fenologia e produtividade da amoreira-preta cultivar Xavante na região de Guarapuava-PR.

\section{MATERIAL E MÉTODOS}

A pesquisa foi conduzida em área experimental da Universidade Estadual do CentroOeste (UNICENTRO) em Guarapuava-PR, localizada a $25^{\circ} 23^{\prime} 36^{\prime \prime}$ de latitude sul e $51^{\circ} 27^{\prime} 19^{\prime \prime}$ de longitude oeste e a $1.120 \mathrm{~m}$ de altitude. O clima é classificado segundo Köppen como subtropical mesotérmico-úmido ( $\mathrm{Cfb}$ ), sem estação seca, com verões frescos e inverno moderado. O solo é classificado como latossolo bruno distroférrico.

A área experimental foi preparada entre maio e agosto de 2004, de acordo com as recomendações preconizadas para a cultura (Antunes \& Raseira, 2004). Neste período também foi instalado o sistema de condução em dupla espaldeira. As mudas foram obtidas do Centro de Pesquisa Agropecuária de Clima Temperado da Embrapa em Pelotas-RS, tendo sido plantadas em setembro de 2004 no espaçamento $1,0 \times 4,0 \mathrm{~m}$. As plantas foram podadas em 02.08.2005, 05.08.2006 e 04.08.2007 eliminando os ramos que já haviam produzido e encurtando os ramos anuais em cerca de $40 \mathrm{~cm}$ do solo, acima de uma gema.

Vinte plantas foram previamente identificadas para as avaliações. Nos anos de 2005, 2006 e 2007 foram avaliadas semanalmente as seguintes variáveis: porcentagem de brotação de todas as gemas mantidas após a poda, a partir da abertura das primeiras gemas quando adquiriram tonalidade esverdeada na ponta; e porcentagem de florescimento, calculado a partir da contagem semanal de todas as flores abertas de cada planta.

Os frutos foram colhidos duas a três vezes por semana, a partir do momento em que os frutos apresentavam coloração preta arroxeada. Imediatamente após a colheita, foi realizada a pesagem dos frutos em balança de precisão, calculando-se a produção por planta e a estimativa de produtividade (t ha ${ }^{-1}$ ). Avaliou-se também em 2005 e 2006 a massa média dos frutos e o teor de sólidos solúveis totais expresso em ${ }^{\circ}$ Brix com auxilio de um refratômetro digital com autocompensação de temperatura segundo a metodologia de Carvalho et al. (1990). Para esta análise, foram utilizados 20 frutos coletados de cada planta, na última semana de dezembro.

O delineamento experimental foi inteiramente casualizado com três tratamentos (anos), 20 repetições e parcela experimental constituída por uma planta. Os dados foram submetidos à análise de variância e diferenças entre dois tratamentos maiores que a soma de dois desvios padrões foram considerados significantes $(P=0,05)$ (Moretti et al., 2002).

\section{RESULTADOS E DISCUSSÃO}

O início da brotação da amoreira-preta cv. Xavante em Guarapuava-PR situou-se entre 12 e 18 de agosto, ou seja, 10 a 14 dias após a poda, dependendo do ano, estendendo-se até o final de setembro (Figura 1). Segundo Antunes et al. (2000), os aspectos fenológicos da amoreira-preta podem variar de ano para ano em função da exigência em frio ter sido ou não satisfeita. Além de aspectos climáticos, fatores inerentes à espécie e/ou 
variedade podem afetar o comportamento da planta. A amoreira-preta cv. Xavante apresentou boa brotação das gemas durante os três anos de avaliação, atingindo 95,88 e $96 \%$ de brotação em 2005, 2006 e 2007, respectivamente (Figura 1); demonstrando boa adaptação climática em Guarapuava-PR, em relação ao requerimento de acúmulo de frio para a superação da dormência. Segundo Botelho et al. (2006), Guarapuava apresenta média de 308,6 horas de frio, condições que atendem as necessidades da amoreira-preta cv. Xavante, que é considerada de baixa exigência em frio (Antunes \& Raseira, 2004).

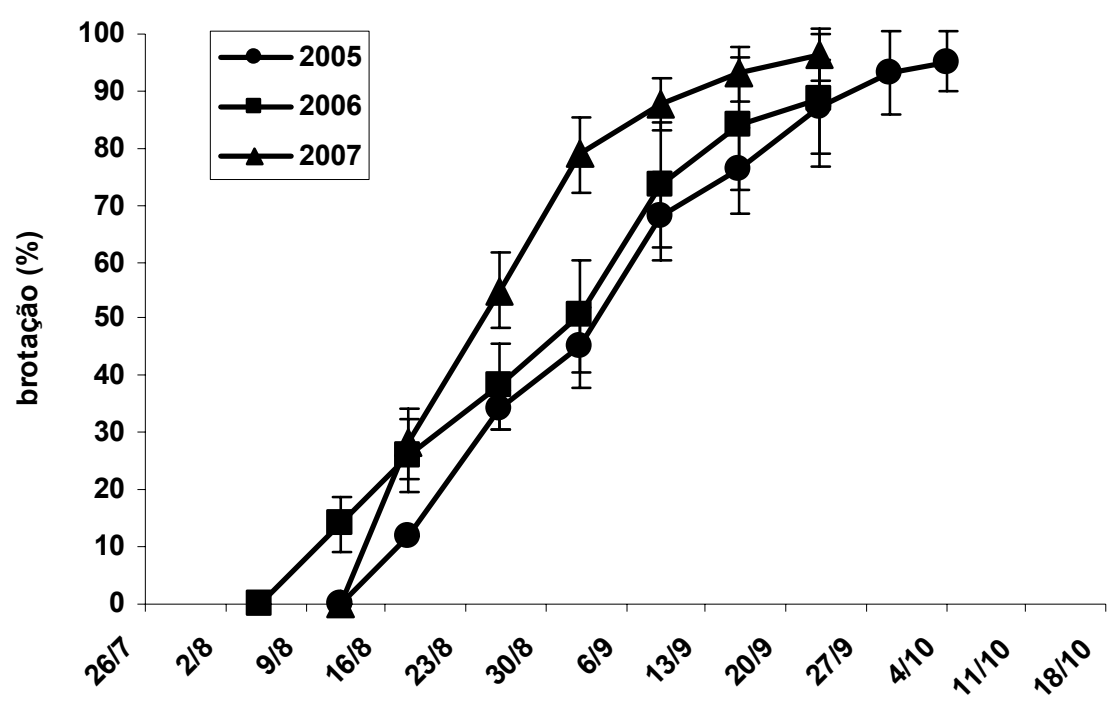

FIGURA 1 - Porcentagem (\%) de brotação em plantas de amoreira-preta cv. Xavante em Guarapuava-PR, durante o período de 2005 a 2007. As barras verticais representam o desvio padrão $(n=20)$.

O florescimento iniciou-se no começo de outubro em todos os anos de avaliação, estendendo-se entre as datas de 18 e 25 de novembro, entretanto, verifica-se que em 2007 o florescimento foi mais precoce (Figura 2). A porcentagem de $50 \%$ de flores abertas foi atingida em meados de outubro em 2007, no final de outubro em 2006, e em meados de novembro em 2005. Estes resultados contrastam com os apresentados por Antunes et al. (2000), que verificaram em Minas Gerais que as cultivares Seleção 97, Brazos, Tupy, Cherokee, Caingangue, Guarani e Comanche iniciaram a floração em setembro, à exceção da cv. Ébano com inicio em outubro, sendo que todas permaneceram na fase de florescimento por até 85 dias. Peruzzo et al. (1995) observaram, em Videira (SC), que 'Brazos' iniciou a floração na segunda semana de setembro e 'Caingangue' na terceira semana. 'Tupy', 'Comanche', 'Guarani', 'Cherokee' e 'Ébano' tiveram floração distribuída pelo mês de outubro.

As variações de florescimento em diferentes regiões podem ser em função da quantidade de horas de frio acumuladas pelas plantas, decorrente das oscilações térmicas que ocorrem de uma região para outra, como também pode estar relacionado à data de início de temperaturas elevadas favoráveis ao crescimento. Essa diferença de comportamento pode ter ocorrido devido às condições climáticas encontradas em Minas Gerais por Antunes et al. (2000), com inverno mais ameno, diminuindo o período de repouso das plantas e, conseqüentemente, floração mais antecipada.

Estes dados contrastam também com os apresentados por Antunes \& Raseira (2004), que avaliaram o comportamento da amoreira-preta 'Xavante' nas condições do Sul do Brasil, onde a floração deu-se do início em setembro e estendendo-se até outubro.

Nas condições do Rio Grande do Sul, a variedade de amoreira-preta 'Ébano' inicia a floração na segunda quinzena de outubro, estendendo-se até o início de novembro (Bassols \& Moore, 1981; EMBRAPA, 1981), muito semelhante ao observado para a cv. Xavante em GuarapuavaPR.

Nos três anos de estudo a cv. Xavante teve colheita realizada no período de final de novembro até final de janeiro, com pico de colheita entre o final de dezembro e início de janeiro, para as condições de Guarapuava-PR (Figura 3). Em 2007, no entanto, foi verificado mais um pico de colheita no início de dezembro. Estes resultados não foram muito diferentes do observado para a cv Ébano nas condições do Rio Grande do Sul em que o período de colheita se estendeu de meados de dezembro a início de fevereiro (Bassols \& Moore, 1981; EMBRAPA, 1981). Em Jundiaí-SP, a cV. Ébano teve colheita concentrada entre a segunda quinzena de janeiro e a primeira de fevereiro (Martins \& Pedro Júnior, 1999). Por outro lado, a maturação da cv. Xavante é mais precoce no Rio Grande do Sul com colheita iniciando em meados de novembro (Antunes \& Raseira, 2004). Peruzzo et al. (1995) observaram, em Videira (SC), que 'Tupy', 'Comanche', 'Guarani', 'Cherokee' e 'Ébano' tiveram período de colheita da segunda semana de novembro à terceira semana de janeiro. 


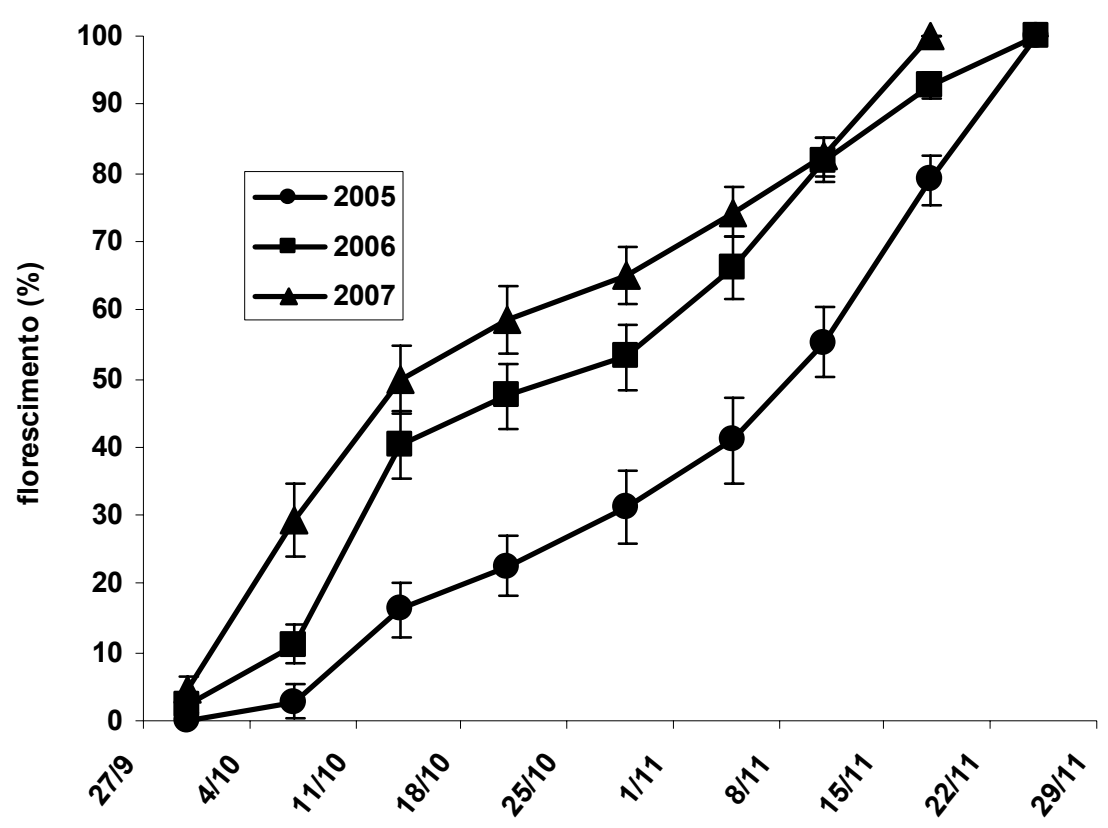

FIGURA 2 - Florescimento (\%) da amoreira-preta cv. Xavante em Guarapuava-PR, durante o período de 2005 a 2007. As barras verticais representam o desvio padrão $(n=20)$.

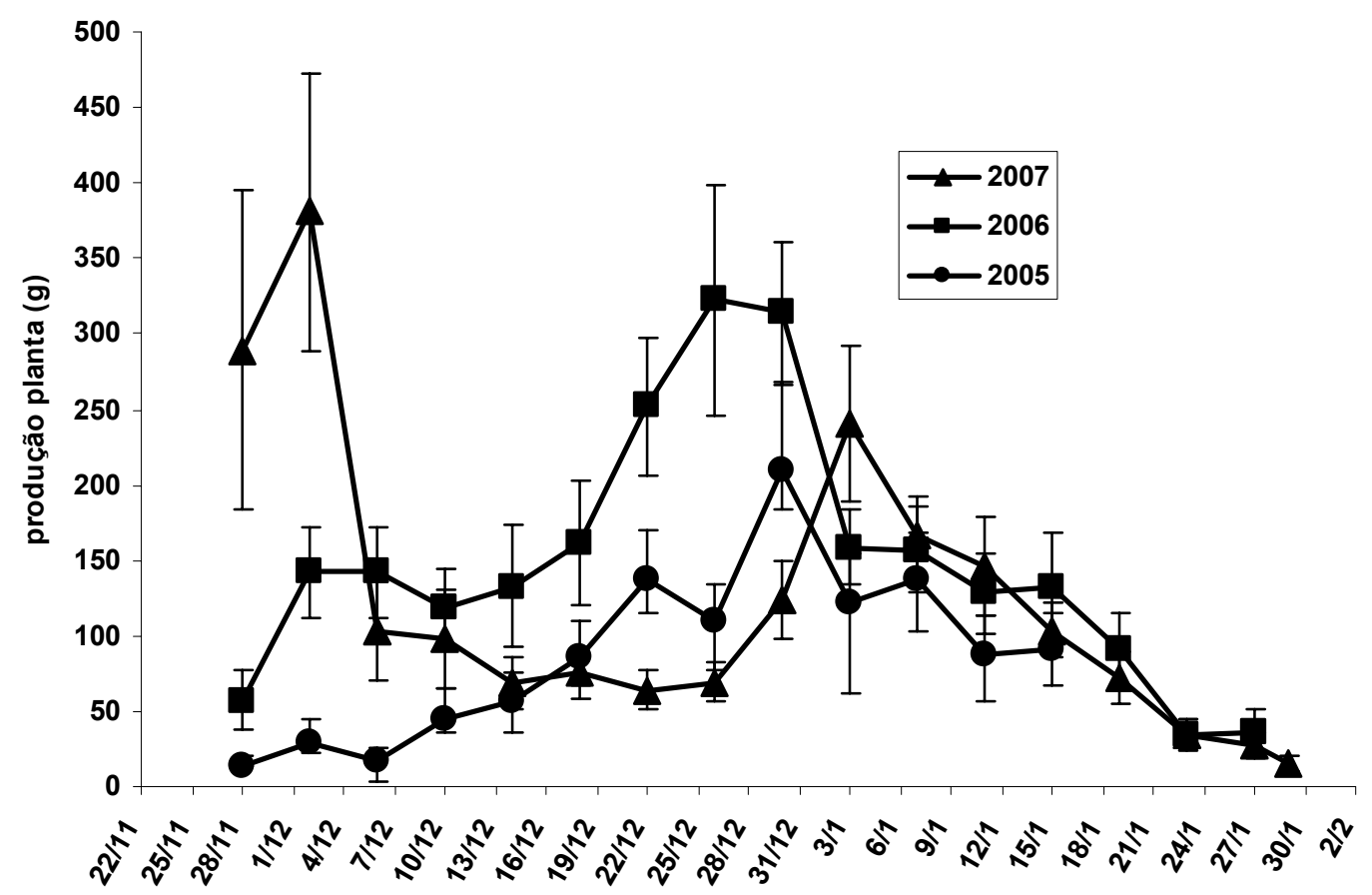

FIGURA 3 - Produção por planta (g) da amoreira-preta cv. Xavante em Guarapuava-PR durante o período de 2005 a 2007. As barras verticais representam o desvio padrão $(n=20)$.

Em relação às produtividades estimadas da cv. Xavante, estas foram de 2.790,5; 5.952,9 e $5.199,1 \mathrm{~kg} \mathrm{ha}^{-1}$, para os anos de 2005, 2006 e 2007, respectivamente (Figura 4), muito superiores às produtividades relatadas para a 'Ebano', outra cultivar sem espinhos. Em Jundiaí-SP, a cv. Ébano apresentou produtividade variando de 1.786 a 2.900 $\mathrm{kg} \mathrm{ha}^{-1}$, em função do ano agrícola, independente do espaçamento de plantio (Martins \& Pedro Júnior, 1999). Antunes et al. (2006) estudando o comportamento de diferentes cultivares de amoreira-preta por três safras consecutivas, verificaram as seguintes médias de produtividade $(\mathrm{t}$ ha $\left.^{-1}\right)$ : Brazos $(13,22)$, Tupy $(10,58)$, Guarani $(13,59)$, Caigange $(6,80)$, Cherokee $(2,85)$, Seleção 97 $(2,07)$, Ébano $(2,97)$, Comanche $(9,98)$. 


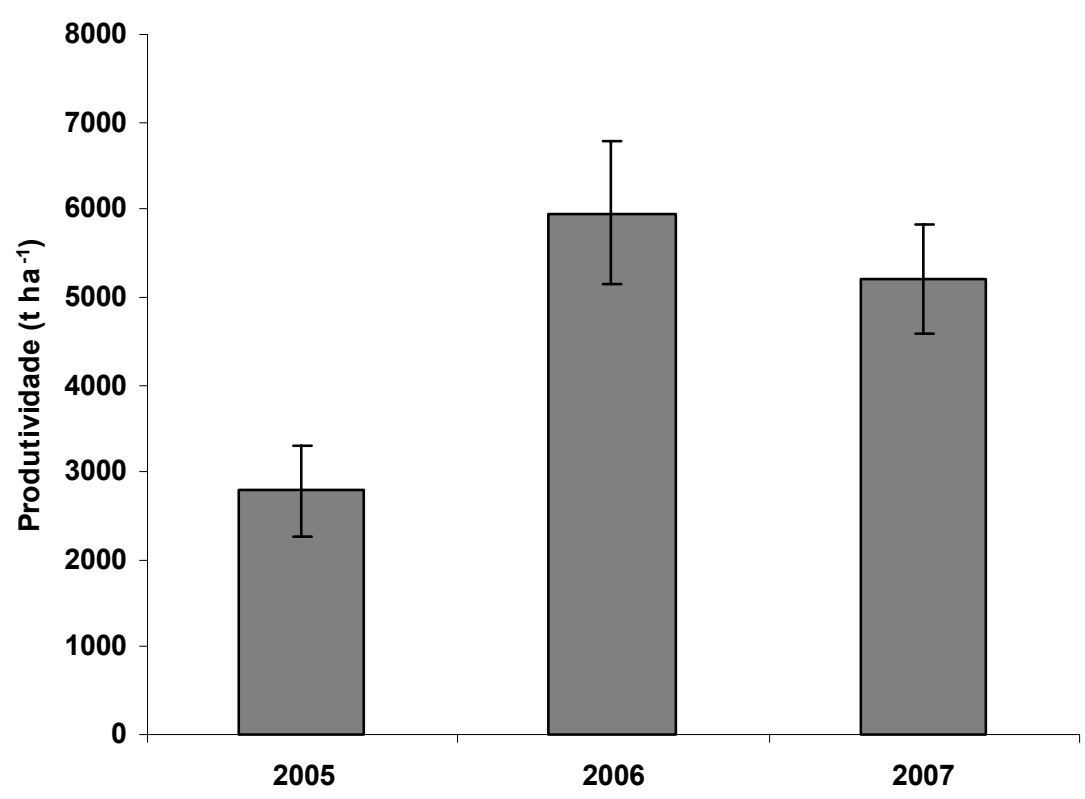

FIGURA 4 - Produtividade ( $\mathrm{t} \mathrm{ha}^{-1}$ ) da amoreira-preta cv. Xavante em Guarapuava-PR. As barras verticais representam o desvio padrão $(n=20)$.

A massa média dos frutos da amora-preta cv. Xavante atingiu em Guarapuava-PR médias de 5,1 e 4,7 g, em 2005 e 2006, respectivamente. Peruzzo et al. (1995) verificaram em Videira (SC) as seguintes massas médias: 'Brazos' $(3,1 \mathrm{~g})$, 'Tupy' (5,6g), 'Caingangue' ( $4,4 \mathrm{~g})$, 'Guarani' (4,1 g), 'Comanche' (3,8 g), 'Cherokee' $(4,4$ g) e 'Ébano' (2,4g). Com exceção de 'Tupy' estes resultados foram inferiores aos obtidos em Guarapuava pela cv. Xavante. Antunes \& Raseira (2004) caracterizaram a amora-preta cv. Xavante com massa média próxima a $6 \mathrm{~g}$. Esta diferença pode ser devida a problemas com a polinização, apesar de a amoreira-preta ser autofértil (Bassols \& Moore, 1981); com interferências ambientais, tais como vento e chuva na florada ou pela redução no número de drupetes, em função da presença de insetos, como coleópteros, que poderiam alimentarse dos estigmas e estames, provocando redução no pegamento e da massa final do fruto. Em CaldasMG, Antunes et al. (1999), estudando o comportamento de oito cultivares de amoreira-preta por três anos consecutivos, verificaram valores de massa média entre 3,63 (cv. Ébano) e 6,40 g (cv. Tupy).

Em relação ao teor de sólidos solúveis, a cultivar Xavante apresentou valores médios de 10,1 e $8,3 \%$, em 2005 e 2006 , respectivamente. Antunes \& Raseira (2004) relataram os seguintes valores médios para as diferentes cultivares: Brazos com 8 a $8,5 \%$, Caingangue com valores próximos a $11 \%$, Cherokee em torno de 8 a $9 \%$, Guarani com teores entre 8 e 10\%, Tupy em torno de 8 e $9 \%$ e Xavante com valores de $8 \%$.

\section{CONCLUSÕES}

1) A cv. Xavante apresenta boa adaptabilidade para a região de Guarapuava com brotação regular entre a segunda quinzena de agosto e final de setembro, floração entre início de outubro e meados de novembro e colheita de final de novembro até o final de janeiro.

2) A produtividade situou-se entre $2.790,5 \mathrm{e}$ $5.952,9 \mathrm{t} \mathrm{ha}^{-1}$, a massa média de frutos entre $5,1 \mathrm{e}$ $4,7 \mathrm{~g}$ e o teor de sólidos solúveis entre 8,3 e 10,1\%, considerados adequados para a cultura da amoreira-preta no Brasil.

\section{AGRADECIMENTO}

Ao Centro de Pesquisa Agropecuária de Clima Temperado/ - CPACT/Embrapa pela doação das mudas de amoreira-preta cv. Xavante para este experimento.

\section{REFERÊNCIAS}

1. ANTUNES, L. E. C. Amora-preta: nova opção de cultivo no Brasil. Ciência Rural, v. 32, n. 1, p. 151-158, 2002.

2. ANTUNES, L. E. C. Aspectos fenológicos, propagação e conservação pós-colheita de frutas de amoreira-preta (Rubus spp) no sul de Minas Gerais. 1999. 129 p. Tese (Doutorado em Fitotecnia) - Curso de Pósgraduação em Agronomia, Universidade Federal de Lavras, Lavras, 1999.

3. ANTUNES, L. E. C. Potencial de produção de pequenas frutas em diferentes regiões do Sul do Brasil. In: ENCONTRO NACIONAL DE FRUTICULTURA DE CLIMA TEMPERADO DO SUL DO BRASIL, 8, 2005, Caçador. Anais... Caçador: EPAGRI, 2005. v. 1, p. 61-63. 
BOTELHO, R.V. et al. Fenologia e produção da amoreira-preta...

4. ANTUNES, L. E. C. et al. Blossom and ripening periods of blackberry varieties in Brazil. Journal American Pomological Society, v. 54, n. 4, p. 164-168, 2000.

5. ANTUNES, L. E. C.; RASEIRA, M. do C. B. Aspectos técnicos da cultura da amora-preta. Pelotas: Embrapa Clima Temperado, 2004. 54 p. (Documento, 122)

6. ANTUNES; L.E.C. et al. Produção extemporânea de amora-preta. Revista Brasileira de Fruticultura, v. 28, n. 3, p. 430434, 2006.

7. BASSOLS, M. do C. M.; MOORE, J. N. 'Ébano' thornless blackberry. Hortscience, v. 16, n. 5, p. 686-687, 1981.

8. BOTELHO, R. V.; AYUB, R. A.; MÜLLER, M. M. L. Somatória de horas de frio e de unidades de frio em diferentes regiões do estado do Paraná. Scientia Agraria, v. 7, n. 1-2, p. 89-96, 2006.

9. CARVALHO, C. R. L. et al. Análises químicas de alimentos. Campinas: Instituto de Tecnologia de Alimentos, 1990. 121 p.

10. EMPRESA BRASILEIRA DE PESQUISA AGROPECUÁRIA (EMBRAPA). Lançamento de cultivares. Pelotas: UEPAE de Cascata, 1981. 16 p. (Documentos, 1)

11. FÁVARO, J. L.; SALVADOR, E. D.; FÁVARO JÚNIOR, J. L. A presença da agricultura familiar na região de GurapuavaPR. In: SEMANA DE ESTUDOS AGRONÔMICOS DA UNICENTRO, 2, Guarapuava, 2004. Anais... Guarapuava: Editora Unicentro, 2004. v. 1, p. 11-19.

12. MARTINS, F. P.; PEDRO JÚNIOR, M. J. Influência do espaçamento na produtividade da amora-preta, cv. ébano, em Jundiaí-SP. Bragantia, v. 58, n. 2, p. 317-321, 1999.

13. MORETTI, C. L. et al. Respiratory activity and browning of minimally processed sweet potatoes. Horticultura Brasileira, v. 20, n. 3, p. 497-500, 2002.

14. PERUZZO, E. L.; DALBÓ, M. A.; PICCOLI, P. S. Amora-preta: variedades e propagação. Agropecuária Catarinense, v. 8, n. 3, p. 53-55, 1995.

15. PROGRAMA DAS NAÇÕES UNIDAS PARA O DESENVOLVIMENTO HUMANO (PNUD-BRASIL). Atlas do Desenvolvimento Humano. 2004. Disponível em: <http://www.pnud.org.br/atlas/>. Acesso em: 19 set. 2008.

Recebido em 08/10/2008 Aceito em 20/01/2009 